\title{
Infant Motor Development Recovery after Surgery of Post Traumatic Epilepsy (PTE) - Meaningful Change of Fractional Anisotropy (FA) of MRI Diffusion Tensor Imaging (DTI) in a Case of Growing Skull Fracture
}

Satoko Ochi ${ }^{1^{*}}$, Kazuhisa Yoshifuji ${ }^{1,2}$, Toshihide Watanabe ${ }^{3}$ and Nobuhiro Mikuni ${ }^{1}$

${ }^{1}$ Department of Neurosurgery, Sapporo Medical University, Japan

${ }^{2}$ Department of Pediatric Neurosurgery, Hokkaido Children's Hospital and Rehabilitation Center, Japan

${ }^{3}$ Department of Pediatric Neurology, Hokkaido Children's Hospital and Rehabilitation Center, Japan

*Corresponding author: Satoko Ochi, Department of Neurosurgery, Sapporo Medical University South 1, West 16, Chuo-ku, Sapporo, Japan, Tel: 81-11-611-2111 (ext. 3351); Fax: 81-11-614-1662; E-mail: ochi@sapmed.ac.jp

Rec date: Jul 22, 2016; Acc date: Jul 29, 2016; Pub date: Jul 30, 2016

Copyright: @ 2016 Ochi S, et al. This is an open-access article distributed under the terms of the Creative Commons Attribution License, which permits unrestricted use, distribution, and reproduction in any medium, provided the original author and source are credited.

\begin{abstract}
Epileptic seizure in pediatric patients affects neurodevelopment, and surgical treatment of intractable epilepsy improved comorbidities, but the mechanism is not fully uncovered yet. By measurement of MRI-DTI Fractional Anisotropy (FA) of posterior limb of internal capsule (PIC) of infants, we presented its change by seizure propagation and control in a case of an infant post traumatic epilepsy (PTE) caused by growing skull fracture. Her motor developmental delay and hemiparesis with non-convulsive status epilepticus (NCSE) started 2 months after injury, recovered after surgical repair and seizure control. FA of PIC was lower than normal (0.29 ipsilateral, 0.37 contralateral) had increased to normal range in one week after surgical treatment and seizure control $(0.62,0.66)$. Comparing with normal time course of FA of motor tract of infant, this dynamic change of FA indicated the effect of seizure control after surgical treatment. As measurement of other brain lesion also showed increased FA in both ipsilateral and contralateral deep white matter, indicated the effect of NCSE for wide network of brain, and influenced infant neuronal development. These result indicated one mechanism why NCSE affected motor developmental delay and surgical intervention for regional infant intractable epilepsy prevented further developmental delay. By handy method of measuring FA of motor tract, we had one possibility to predict motor tract injury in infancy. We also reviewed and discussed about the mechanism of FA increase and decrease in early infancy and how PTE caused FA change.
\end{abstract}

Keywords: Post Traumatic Epilepsy (PTE); Non-Convulsive Status Epilepticus (NCSE); Diffusion Tensor Imaging Fractional Anisotropy (DTI-FA); Motor development growing skull fracture

\section{Introduction}

It is well recognized that epileptic seizure in pediatric patients affect neurodevelopment, [1-6] further and early surgery for pediatric intractable epilepsy are recommended. It is more so in infant, when white matter myelination is in process, and brain development accomplished with in-born stepwise processes. The report of the development of early white matter motor tract by MRI DTI fractional anisotropy (FA) showing drastic increase by the end of 6 months of age, and gradual increase continues until adulthood [7-12]. But the mechanism of how seizure propagation influence white matter developmental in each type of epilepsy is not fully uncovered yet $[6,13]$. To prevent developmental delay in infants after traumatic brain injury or post-traumatic epilepsy (PTE), it is needed to clear why status epileptics result profound retardation [14-16].

We report a case of 7 month old girl suffering from non-convulsive status epileptics (NCSE) due to PTE, which caused by growing skull fracture and occipital brain protrusion. Her seizure propagated in 2 month after trauma, and resulted mild left hemiparesis and motor development delay. Pre-operational MRI-DTI fractional anisotropy (FA) revealed profound decrease of FA, not only occipital lobe, but also opposite hemisphere, which recovered in 1 week after operation, and her development normalized. It presents one mechanism of how PTE and NCSE affect infant neurodevelopment, by comparing with normal time course.

\section{Method and Materials}

MRI DTI image was applied using MRI (GE Signa, 1.5T), Pulse sequence, EPI; TE $92.2 \mathrm{msec}$; TR $10000 \mathrm{msec}$; Matrix, $128 \times 128$; FOV, $26 \mathrm{~mm}$; b-value, 1000; slice depth $4 \mathrm{~mm}$ gapless, with MPG 15 axis. Fractional anisotropy (FA) was measured using manual ROI on both posterior limb of internal capsule (PIC), Pedunculus cerebri $(\mathrm{PuC})$. Accuracy of this method was measured by 3 different pediatric neurologist and neurosurgeon, of 10 samples, and statistically analyzed.

\section{Case Presentation}

This is a case of a 7 months old girl, with nothing particular in her family history and past medical history. She was born by normal delivery without any developmental problems. At the age of 4 months, she got injured by car- to- car traffic accident, and transferred to an emergency hospital, and was diagnosed as complex skull fracture, with brain contusion in right occipital lobe. After 2 weeks, she discharged without any apparent neurological defect, with protective medication of antiepileptic drug; phenobarbital (PB). 
Citation: Ochi S, Yoshifuji K, Watanabe T, Mikuni M (2016) Infant Motor Development Recovery after Surgery of Post Traumatic Epilepsy (PTE) Meaningful Change of Fractional Anisotropy (FA) of MRI Diffusion Tensor Imaging (DTI) in a Case of Growing Skull Fracture. J Neurol Disord 4: 284. doi:10.4172/2329-6895.1000284

Page 2 of 4

She suffered first partial seizure on her left leg at 42 days after accident, which propagated to left upper limb in a week. In one month later, her seizure increased its severity and frequency, propagated to the other side and mouth. Pediatrician started Carbamazepine (CBZ), and Phenytoin (PHT), which was in vain. By the end of 2 months after accident, she suffered status most of the day and readmitted. Radiological exam revealed progressive skull fracture with right occipital brain protrusion, and slight subdural hematoma (Figure 1: A, $\mathrm{B}$ and C). She was transferred to Children's hospital.

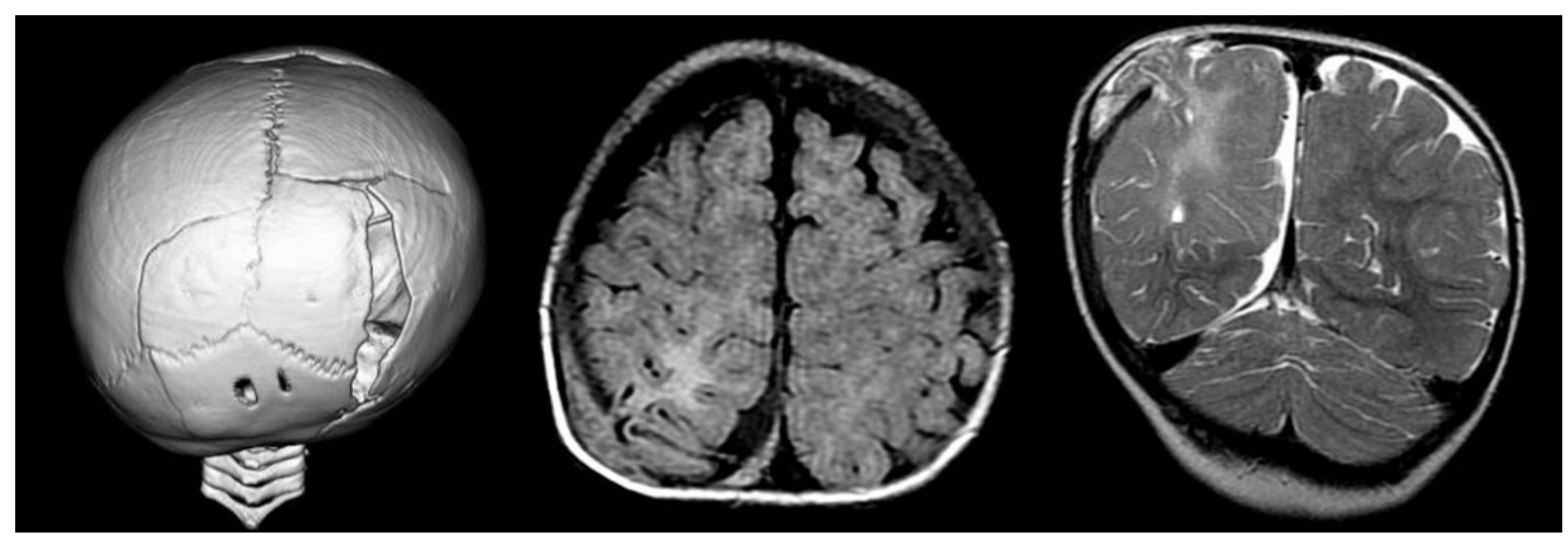

Figure 1: Radiological exam revealed progressive skull fracture with right occipital brain protrusion, and slight subdural hematoma.

On admission, she was well-nourished baby, with left hemiparesis (3 4/5). She could not sit alone with eyes deviated to right, which was proved to be caused by non-convulsive status epileptics (NCSE) by video EEG. It revealed contentious poly spikes on right parietooccipital, with continuous generalized high voltage slow wave. After injection of midazolam (MDZ) $0.065 \mathrm{mg} / \mathrm{kg}$, her hemiparesis improved, and she could keep sitting alone. To stop NCSE, continuous injection of $\mathrm{MDZ}(0.1 \sim 0.2 \mathrm{mg} / \mathrm{kg} / \mathrm{hr}$.) was needed until operation. Surgical repair was carried out, which consisted with resection subosteal protruded brain, removal of subdural hematoma, repair of dura matter and skull with auto graft. With perioperative transient MDZ infusion, she shows good recovery from hemiparesis in a week. By the end of 2 month, she discharged with levetilazetam (LEV) monotherapy. After 5 years, she showed normal development, without any seizure.

\section{Result}

Accuracy of measurement of FA/PIC and FA/PuC showed good correlation, with coefficient number 0.95 .

This 7 month old infant with NCSE resulted in hemiparesis, which had recovered after the injection of Midazolam. She showed good recovery after surgical repair, not only in short term, but also long term. Compare with normal FA of motor tract, FA of 67 days after trauma was below the normal range. Ipsilateral FA of internal capsule showed drastic increase from 0.29 (before surgery) to 0.628 (right FA/ PIC), 0.2 (before) to 0.42 (right FA/PuC) in a week. Contralateral FA showed also increase, from 0.37 (before) to 0.66 (left FA/PIC), from 0.25 to 0.39 (left FA/PuC) (Figure 2).

Pathological specimen showed prominent gliosis in and around protruded brain area, Immunostaining revealed loss of neuronal cell, and by CD 68 and GFAP staining indicated perivascular lamellar like accumulation of histiocytic and gliosis.

\section{Discussion}

We presented a case of PTE infant, resulting in drug resistant epilepsy in 2 months after injury, whose motor developmental delay accompanied with seizure propagation. MRI was of value to diagnose growing skull fracture $[17,18]$. Preoperative low FA of motor tract white matter showed drastic increase after surgical treatment, detected by MRI DTI. Because of short duration, it should not be caused by normal process of development, such as myelination, rather because of physiological condition, such as seizure control. Interestingly, this change of increase was seen not only ipsilateral, but also contralateral white matter, and also, wide range of brain region. Her symptom of hemiparesis and motor developmental delay was recovered after surgery as epileptic seizure controlled. This indicated white matter abnormalities in this infant deeply influenced by continuous seizure, along with motor symptom, and seizure control related with white matter development.

In studies of adult drug resistant epilepsy (DRE), such as temporal lobe epilepsy with hippocampal sclerosis (HS), for example, widespread white and grey matter abnormalities were reported by using DTI FA images [19] or voxel-based morphometric were observed [20]. Diffuse abnormal FA decrease of ipsilateral temporal white matter coexist with wide spread myelin degeneration or maldevelopment were detected, resulting the abnormal structural connectivity [21].

It is reported, factors of FA increase indicate progress of myelination $[8,22]$, increase of axonal diameter, fiber bundle density, immature oligodendrocyte proliferation $[9,23]$, in development. Instead, factors of decrease are axonal injuries, such as axonal swelling or disconnection, delay of myelination, demyelination, gliosis or ischemia related with epilepsy [19]. What we demonstrated in this report is not white matter reversibility, but rather normalized development by removing epileptogenic cause. Her post traumatic late seizure started from left hand to leg, and contralateral limb, then to mouth. This propagation related with anatomical localization of legion. 
Citation: Ochi S, Yoshifuji K, Watanabe T, Mikuni M (2016) Infant Motor Development Recovery after Surgery of Post Traumatic Epilepsy (PTE) Meaningful Change of Fractional Anisotropy (FA) of MRI Diffusion Tensor Imaging (DTI) in a Case of Growing Skull Fracture. J Neurol Disord 4: 284. doi:10.4172/2329-6895.1000284

Page 3 of 4

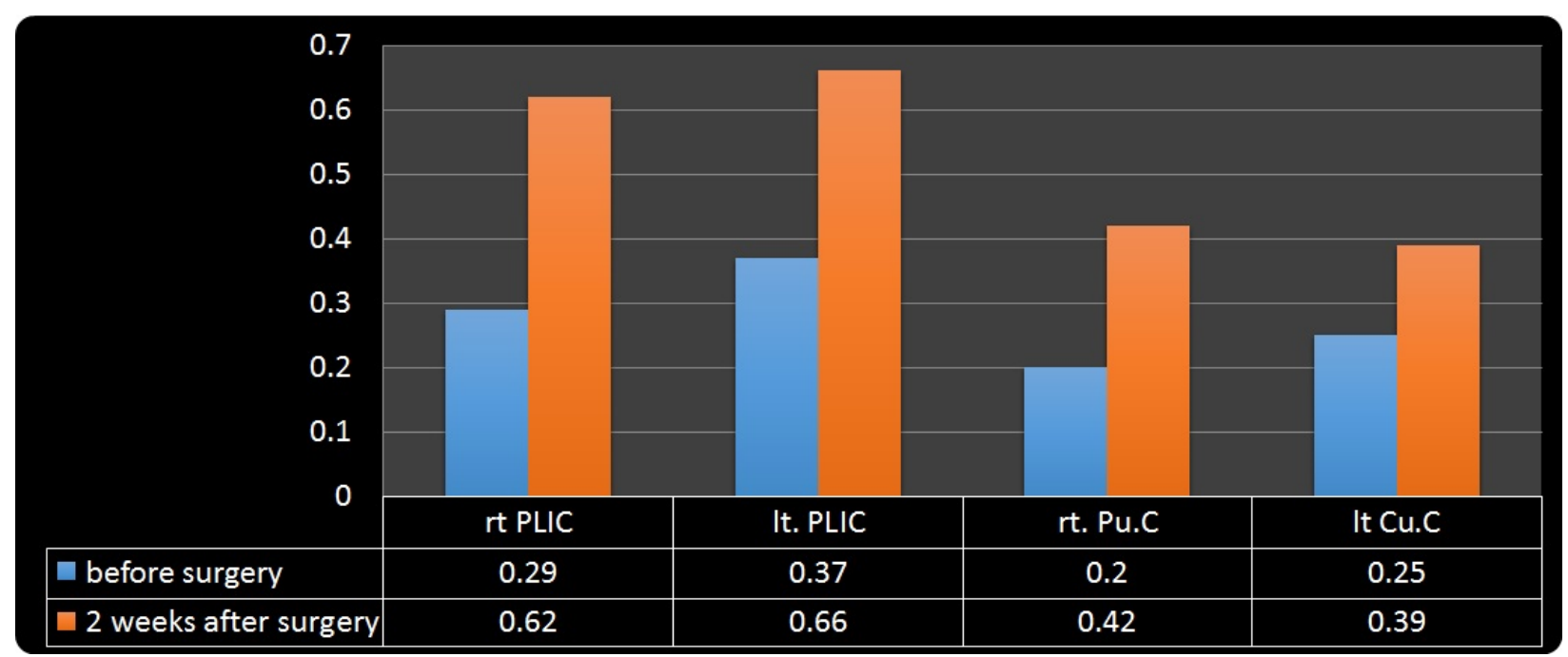

Figure 2: FA change.

The pathological specimen of resected brain revealed profound gliosis, lack of neuron in central region, and OD-68 positive cell and GFAP positive glial cell accumulate lamellar like around the vessels periphery, which indicates responsive reaction of the damaged brain. About the pathogenesis of PTE, evidences were discussing, such as albumin leakage affecting glial spatial buffering effect of astrocyte, and TGF-ßreceptor and glutamate transporter function [24-27]. Also glia derived brain dysfunction because Blood Brain Barrier dysfunction (BBBD), perivascular Ig-G and albumin induced isogenies [28-34]. As free $\mathrm{Fe}$ and calcium disturbed normal cycle of heme-protein aroused by contusion, leading formy spheroid body leads epileptogenesis [35]. In addition, leukocyte-BBB interaction is also reported to facilitate seizure. These reaction, induced localization related epilepsy and NCSE, and NCSE also induced BBBD, as a vicious cycle in this patient. In pediatric developmental brain, incidence of PTE is reported higher in acute subdural hematoma than diffuse axonal injury. And far worse developmental outcome resulted in cases of child abuse syndrome than in traffic accident [14]. Concerning about antiepileptic drugs for PTE, neither phenytoin (PHT), phenobarbital (PB) nor valproic acid (VPA) were reported meaningful effect for the epileptogenesis [36], in contrast, levetiracetam (LEV) has merit to prevent it $[37,38]$, suggesting favorable to the PTE patient $[39,40]$.

Given that child neurodevelopment depend on widespread network in the brain [39], it is easily suspected diffuse white matter damage by PTE NCES would affect not only motor function but other mental development. The drastic change FA of white matter of this case teaches us the need of early treatment for functional recovery of children of localization related drug resistant epilepsy due to PTE.

\section{Conclusion}

In infant PTE, seizure influence white matter development not only damaged area but fur beyond to the contralateral motor system, affecting neurodevelopment. To prevent motor developmental delay of PTE infant, accurate diagnosis and treatment of epilepsy were recommended.

\section{References}

1. Agrawal A, Timothy J, Pandit L, Manju M (2006) Post-traumatic epilepsy: an overview. Clin Neurol Neurosurg 108: 433-439.

2. Aronica E, Ravizza T, Zurolo E, Vezzani A (2012) Astrocyte immune responses in epilepsy. Glia 60: 1258-1268.

3. Bellander BM, Singhrao SK, Ohlsson M, Mattsson P, Svensson M (2001) Complement activation in the human brain after traumatic head injury. J Neurotrauma 18: 1295-1311.

4. Campos BM, Coan AC, Beltramini GC, Liu M, Yassuda CL, et al. (2015) White matter abnormalities associate with type and localization of focal epileptogenic lesions. Epilepsia 56: 125-132.

5. Cercignani M, Inglese M, Pagani E, Comi G, Filippi M (2001) Mean diffusivity and fractional anisotropy histograms of patients with multiple sclerosis. AJNR Am J Neuroradiol 22: 952-958.

6. Choi J, Koh S (2008) Role of brain inflammation in epileptogenesis. Yonsei Med J 49: 1-18.

7. Christensen J, Pedersen MG, Pedersen CB, Sidenius P, Olsen J, et al. (2009) Long-term risk of epilepsy after traumatic brain injury in children and young adults: a population-based cohort study. Lancet 373: 1105-1110.

8. Devinsky O, Vezzani A, Najjar S, De Lanerolle NC, Rogawski MA (2013) Glia and epilepsy: excitability and inflammation. Trends Neurosci 36: 174-184.

9. Drobyshevsky A, Song SK, Gamkrelidze G, Wyrwicz AM, Derrick M, et al. (2005) Developmental changes in diffusion anisotropy coincide with immature oligodendrocyte progression and maturation of compound action potential. J Neurosci 25: 5988-5997.

10. Dubois J, Dehaene-Lambertz G, Perrin M, Mangin JF, Cointepas Y, et al. (2008) Asynchrony of the early maturation of white matter bundles in healthy infants: quantitative landmarks revealed noninvasively by diffusion tensor imaging. Hum Brain Mapp 29: 14-27.

11. Fox MD, Snyder AZ, Vincent JL, Corbetta M, Van Essen DC, et al. (2005) The human brain is intrinsically organized into dynamic, anticorrelated functional networks. Proc Natl Acad Sci U S A 102: 9673-9678.

12. Frey LC (2003) Epidemiology of posttraumatic epilepsy: a critical review. Epilepsia 44 Suppl 10: 11-17.

13. Friedman A, Dingledine R (2011) Molecular cascades that mediate the influence of inflammation on epilepsy. Epilepsia 52 Suppl 3: 33-39.

14. Gilmore JH, Lin W, Corouge I, Vetsa YS, Smith JK, et al. (2007) Early postnatal development of corpus callosum and corticospinal white matter 
Citation: Ochi S, Yoshifuji K, Watanabe T, Mikuni M (2016) Infant Motor Development Recovery after Surgery of Post Traumatic Epilepsy (PTE) Meaningful Change of Fractional Anisotropy (FA) of MRI Diffusion Tensor Imaging (DTI) in a Case of Growing Skull Fracture. J Neurol Disord 4: 284. doi:10.4172/2329-6895.1000284

Page 4 of 4

assessed with quantitative tractography. AJNR Am J Neuroradiol 28 1789-1795.

15. Hori M, Ishigame K, Shiraga N, Kumagai H, Aoki S, et al. (2008) Mean diffusivity, fractional anisotropy maps, and three-dimensional whitematter tractography by diffusion tensor imaging. Comparison between single-shot fast spin-echo and single-shot echo-planar sequences at 1.5 Tesla. Eur Radiol 18: 830-834.

16. Husson B, Pariente D, Tammam S, Zerah M (1996) The value of MRI in the early diagnosis of growing skull fracture. Pediatr Radiol 26: 744-747.

17. Janigro D (2012) Are you in or out? Leukocyte, ion, and neurotransmitter permeability across the epileptic blood-brain barrier. Epilepsia 53 Suppl 1: 26-34.

18. Kim SY, Buckwalter M, Soreq H, Vezzani A, Kaufer D (2012) Blood-brain barrier dysfunction-induced inflammatory signalling in brain pathology and epileptogenesis. Epilepsia 53 Suppl 6: 37-44.

19. Kimiwada T, Juhász C, Makki M, Muzik O, Chugani DC, et al. (2006) Hippocampal and thalamic diffusion abnormalities in children with temporal lobe epilepsy. Epilepsia 47: 167-175.

20. Klein P, Herr D, Pearl PL, Natale J, Levine Z, et al. (2012) Results of phase II pharmacokinetic study of levetiracetam for prevention of posttraumatic epilepsy. Epilepsy Behav 24: 457-461.

21. Kurihara M, Shishido A, Yoshihashi M, Fujita H, Kohagizawa T (2012) Prognosis of posttraumatic epilepsy in children. J Jpn Epil Soc 29: 460-469.

22. Kwan P, Schachter SC, Brodie MJ (2011) Drug-resistant epilepsy. N Engl J Med 365: 919-926.

23. Lebel C, Walker L, Leemans A, Phillips L, Beaulieu C (2008) Microstructural maturation of the human brain from childhood to adulthood. Neuroimage 40: 1044-1055.

24. Leung LH, Ooi GC, Kwong DL, Chan GC, Cao G, et al. (2004) Whitematter diffusion anisotropy after chemo-irradiation: a statistical parametric mapping study and histogram analysis. Neuroimage 21: 261-268.

25. Löscher W, Brandt C (2010) Prevention or modification of epileptogenesis after brain insults: experimental approaches and translational research. Pharmacol Rev 62: 668-700.

26. Luat AF, Chugani HT (2008) Molecular and diffusion tensor imaging of epileptic networks. Epilepsia 49 Suppl 3: 15-22.

27. Muhonen MG, Piper JG, Menezes AH (1995) Pathogenesis and treatment of growing skull fractures. Surg Neurol 43: 367-372.
28. Partridge SC, Vigneron DB, Charlton NN, Berman JI, Henry RG, et al. (2006) Pyramidal tract maturation after brain injury in new-borns with heart disease. Ann Neurol 59: 640-651.

29. Pearl PL, McCarter R, McGavin CL, Yu Y, Sandoval F, et al. (2013) Results of phase II levetiracetam trial following acute head injury in children at risk for posttraumatic epilepsy. Epilepsia 54: e135-137.

30. Rugg-Gunn FJ, Eriksson SH, Symms MR, Barker GJ, Thom M, et al. (2002) Diffusion tensor imaging in refractory epilepsy. Lancet 359: 1748-1751.

31. Silver JM, Shin C, McNamara JO (1991) Antiepileptogenic effects of conventional anticonvulsants in the kindling model of epilespy. Ann Neurol 29: 356-363.

32. Statler KD (2006) Pediatric post-traumatic seizures: epidemiology, putative mechanisms of epileptogenesis and promising investigational progress. Dev Neurosci 28: 354-363.

33. Trivedi R, Gupta RK, Shah V, Tripathi M, Rathore RK, et al. (2008) Treatment-induced plasticity in cerebral palsy: a diffusion tensor imaging study. Pediatr Neurol 39: 341-349.

34. Van Diessen E, Diederen SJ, Braun KP, Jansen FE, Stam CJ (2013) Functional and structural brain networks in epilepsy: what have we learned? Epilepsia 54: 1855-1865.

35. Vezzani A, Ravizza T, Balosso S, Aronica E (2008) Glia as a source of cytokines: Implications for neuronal excitability and survival. Epilepsia 49 Suppl 2: 24-32.

36. Weissberg I, Reichert A, Heinemann U, Friedman A (2011) Blood-brain barrier dysfunction in epileptogenesis of the temporal lobe. Epilepsy Res Treat 2011: 143908.

37. Widjaja E, Zamyadi M, Raybaud C, Snead OC, Smith ML (2013) Abnormal functional network connectivity among resting-state networks in children with frontal lobe epilepsy. AJNR Am J Neuroradiol 34: 2386-2392.

38. Willmore LJ, Ueda Y (2009) Post-traumatic epilepsy: Hemorrhage, free radicals and the molecular regulation of glutamate. Neurochem Res 34: 688-697.

39. Wilmshurst JM, Berg AT, Lagae L, Newton CR, Cross JH (2014) The challenges and innovations for therapy in children with epilepsy. Nat Rev Neurol 10: 249-260.

40. Yamamoto M, Moore MH, Hanieh A (1998) Growing skull fracture after cranial vault reshaping in infancy. J Craniofac Surg 9: 73-75. 